\title{
Case report: mismatch repair proficiency and microsatellite stability in gastric cancer may not predict programmed death-1 blockade resistance
}

\author{
Kuo-Hsing Chen ${ }^{1,4,6}$, Chang-Tsu Yuan ${ }^{2}$, Li-Hui Tseng ${ }^{3}$, Chia-Tung Shun ${ }^{2,5,7}$ and Kun-Huei Yeh ${ }^{1,6^{*}}$
}

\begin{abstract}
Background: Anti-programmed death-1 therapy has poor efficacy in mismatch repair-proficient (pMMR) colorectal cancers; however, its efficacy in pMMR gastric cancers remains undetermined. Here, we report the case of a patient with pMMR and microsatellite-stable gastric cancer who exhibited a partial response to salvage anti-programmed death-1 therapy with pembrolizumab.

Case presentation: Initially, the patient underwent subtotal gastrectomy 4 years ago for early-stage gastric cancer (pT1bN2M0, stage IIA). Immunohistochemical analysis of the tumor revealed strongly positive for HER2/neu. He had received trastuzumab plus pertuzumab, cisplatin, and capecitabine for recurrent tumors since September 2014 for 15 cycles. Disease progression of gastric cancer was found in August 2015. Since September 2015, the patient has received pembrolizumab monotherapy (200 mg as a fixed dose, every 3 weeks) for 3 months and the repeat computed tomography demonstrated a confirmed partial response. The plasma carcinoembryonic antigen also decreased dramatically. Both immunohistochemistry and a polymerase chain reaction-based method revealed that the patient had pMMR gastric cancer.

Conclusions: This case report provides the first report that mismatch repair-proficient and microsatellite-stable gastric cancers can respond well to anti-PD-1 monotherapy and indicates both markers may not sufficiently be predictive of anti-PD-1 therapy resistance in gastric cancer.
\end{abstract}

Keywords: Gastric cancer, Immunotherapy, Anti-programmed death-1 antibody, Mismatch repair deficiency, Mismatch repair proficiency, Microsatellite stability

\section{Background}

Immune checkpoint blockade therapies such as those using anti-cytotoxic $\mathrm{T}$ lymphocyte-associated protein 4 antibodies and those blocking programmed death-1 (PD-1) and programmed death ligand-1 (PD-L1) have exhibited promising efficacy in several types of cancer [1-7]. Moreover, the heterogeneous response to immune checkpoint blockade therapy observed in patients in these studies has raised the importance of identifying predictive biomarkers. Mutation or hypermethylation in

\footnotetext{
* Correspondence: khyeh@ntu.edu.tw

${ }^{1}$ Department of Oncology, National Taiwan University Hospital, 7, Chun-Shan S Rd, Taipei 10002, Taiwan

${ }^{6}$ Graduate Institute of Oncology, National Taiwan University, Taipei, Taiwan Full list of author information is available at the end of the article
}

mismatch repair genes (MLH1, MSH2, MSH6, or PMS2) leads to deficient mismatch repair (dMMR) and causes accumulation errors in DNA sequences, thus increasing the risk of colorectal cancer (CRC) and other epithelial cancers [8]. Recently, Le et al. reported that patients with mismatch repair-deficient $\mathrm{CRC}$ and those with mismatch repair-deficient noncolorectal cancer exhibited higher response rates to PD-1 blockade monotherapy (pembrolizumab). In addition, they suggested that hypermutated tumor-associated neoantigens from dMMR are the primary factors affecting the response to anti-PD-1 therapy; previous studies have observed that this therapy stimulated the endogenous immune response $[3,9,10]$. However, Le et al. also reported that none of 18 patients 
with mismatch repair-proficient (pMMR) CRC responded to pembrolizumab, an anti-PD-1 antibody. The efficacy of PD-1 blockade therapy in pMMR noncolorectal cancers and a biomarker for PD-1 blockade remain unknown. Here, we report the case of a 64-year-old man with pMMR and microsatellite-stable (MSS) gastric cancer who exhibited a partial response to salvage pembrolizumab monotherapy.

\section{Case presentation}

A 64-year-old man experienced epigastralgia with tarry stool in late 2011. Esophagogastroduodenoscopy revealed a circular ulcer in the prepyloric area. Biopsy was performed, and the pathology of the specimen revealed gastric adenocarcinoma. On the basis of computed tomography $(\mathrm{CT})$, the gastric cancer was clinically staged as cT3NOM0, stage IIA. He underwent radical subtotal gastrectomy, Billroth II anastomosis, D2 dissection, and cholecystectomy on December 28, 2011. The pathology of the specimen revealed a well-differentiated adenocarcinoma, and Helicobacter pylori infection was not observed (Fig. 1a). Immunohistochemically, tumor cells were strongly positive (3+, according to the proposal by Hofmann et al. [11]) for HER2/neu immunostain (clone 4B5, 1:2 dilution; Fig 1b). The pathological staging of the gastric cancer was pT1bN2M0, stage IIA. After surgery, he was followed up regularly at our hospital without adjuvant treatment.

Two years later, $\mathrm{CT}$ and positron emission tomography revealed tumor recurrence in the left lower paratracheal lymph nodes. The patient was then enrolled in a clinical trial and received 15 cycles of pertuzumab $(840 \mathrm{mg}$ on D1, every 3 weeks) in combination with trastuzumab (562 $\mathrm{mg}$ on D1, every 3 weeks) and chemotherapy $\left(80 \mathrm{mg} / \mathrm{m}^{2}\right.$ cisplatin on $\mathrm{D} 1$ and $1000 \mathrm{mg} / \mathrm{m}^{2}$ capecitabine twice a day on D1-D14, every 3 weeks). He was dropped from the study in August 2015 because the tumors (peritoneal seeding and paraaortic lymph nodes) progressed and his plasma carcinoembryonic antigen (CEA) level increased from 4.78 to $348 \mathrm{ng} / \mathrm{mL}$. The best response of the treatment was stable disease with a firstline progression-free survival of 11 months.

In September 2015, the patient started receiving pembrolizumab (200 $\mathrm{mg}$ as a fixed dose, every 3 weeks) as a second-line treatment for recurrent gastric cancer. No adverse event was observed in the following 2-3 months. Two months later, CT revealed tumor regression and a partial response was confirmed in another CT scan 1 month later (Fig. 2). In addition, the plasma CEA level decreased from 607.1 to $26.96 \mathrm{ng} / \mathrm{mL}$. To investigate the association of the tumor factors with the efficacy of PD1 blockade as well as to confirm whether he had pMMR gastric cancer, we used both immunohistochemistry (IHC) and a polymerase chain reaction-based method (Fig. 3) [12]. In addition, we performed IHC analyses of previous specimens from gastrectomy, which revealed few tumor-infiltrating lymphocytes (TILs) in tumors and invasive fronts, as demonstrated by the presence of CD3 (polyclonal, 1:100), CD4 (clone MT310, 1:50), and CD8 (clone DK-25, 1:200; Fig. 4a-c). Epstein-Barr virus (EBV)-encoded small RNA (EBER) in situ hybridization revealed absence of EBV in the tumor cells (Fig. 4d). The tumor cells were also negative for PD-L1 (B7H1, Abcam, clone ab58810, 1:400; Fig. 5) [13]. Moreover, no polymerase epsilon (POLE) mutation was found by means of Sanger sequencing of exon 9. As of January 2016, the patient was still continuing the pembrolizumab monotherapy with excellent performance status and quality of life.

\section{Discussion}

Evaluations of the efficacy of PD-1 blockade in advanced esophagogastric junction (EGJ) and gastric adenocarcinoma are still preliminary, and an accurate predictive biomarker remains to be determined. Bang et al. reported that the overall response rate of pembrolizumab (by central review) in advanced PD-L1-positive gastric cancer was $22.2 \%$ [95 \% confidence interval, 10.1-39.2] in a phase I study (KEYNOTE-012 study, gastric cancer cohort) [14]. Of the 162 patients screened, 65 were positive for PD-L1.
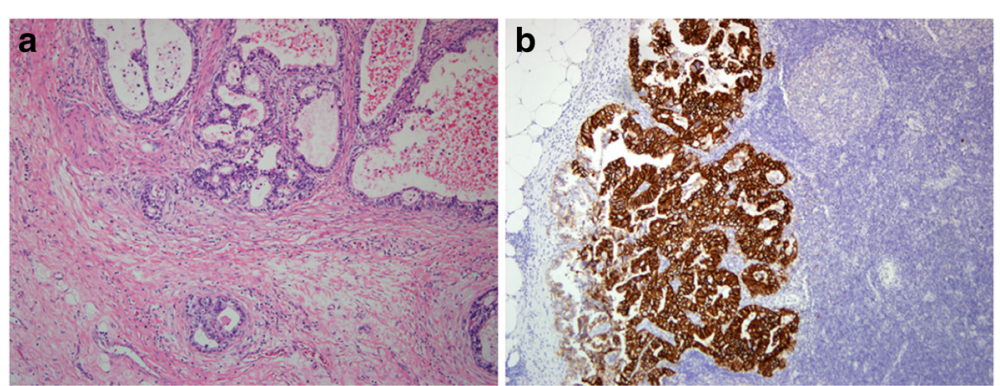

Fig. 1 Histopathology of the gastric cancer and its HER2 immunohistochemistry. Microscopic observation revealed a well-differentiated adenocarcinoma with frequent luminal formation and evident nuclear atypia infiltration within a mild desmoplastic stroma; H \& E stain (a). In the metastasized lymph node, the tumor cells were strongly positive for the HER2/neu immunostain (brown color) (b); original magnification $\times 100$ 


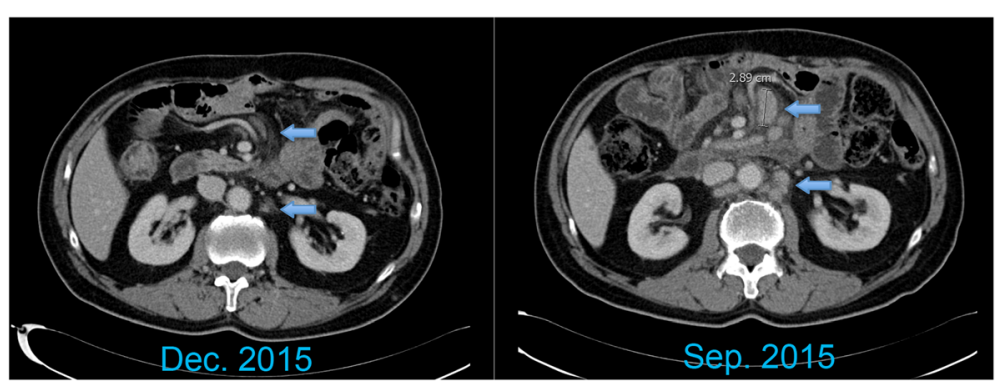

Fig. 2 Computed tomography scan of the recurrent tumors before and after pembrolizumab treatment

The PD-L1 expression was detected through a prototype IHC assay by using the $223 \mathrm{C}$ antibody, and the tumors were determined positive for PD-L1 when PD-L1 staining was observed in the stroma or $\geq 1 \%$ of tumor nest cells. However, PD-L1 expression is not yet a validated predictive biomarker for PD-1 blockade in gastric cancer. Moreover, dMMR has been identified in gastric cancer in several studies with the incidence ranging from 9 to $22 \%$ [15-19]. In a study conducted using the Cancer Genome Atlas (TCGA), $22 \%$ of the tumors belonged to the microsatellite instability (MSI) subtype, with the features of hypermutation and MLH1 silencing. Although pMMR has been shown to predict poor efficacy of PD-1 blockade in $\mathrm{CRC}$, the association of pMMR and PD-1 blockade in EGJ and gastric adenocarcinoma remains unknown. This case report provides the first report that pMMR and MSS gastric cancers can respond well to anti-PD-1 monotherapy. However, larger studies are warranted to explore the association between mismatch repair status and the efficacy of anti-PD-1 therapy in advanced gastric cancer.

The hypothesis that neoantigens from hypermutated tumors may enhance the response of immune checkpoint therapy was supported by clinical correlative studies on melanoma and non-small-cell lung cancer [3, 20, 21]. In addition to dMMR, inactivating POLE mutation, found in CRC, endometrial cancer, and gastric cancer, can result in an extremely high mutation burden $[15,22,23]$. Howitt et al. demonstrated that increased TILs in the tumor microenvironment in POLE-mutated endometrial cancers make these tumors satisfactory candidates for immune checkpoint therapy [23]. We cannot completely exclude the possibility that our patient had a POLE-mutated tumor; however, the incidence of POLE mutation in gastric cancer is very low $(0.47 \%)$ and TILs in the tumor microenvironment were scant in our patient [15].
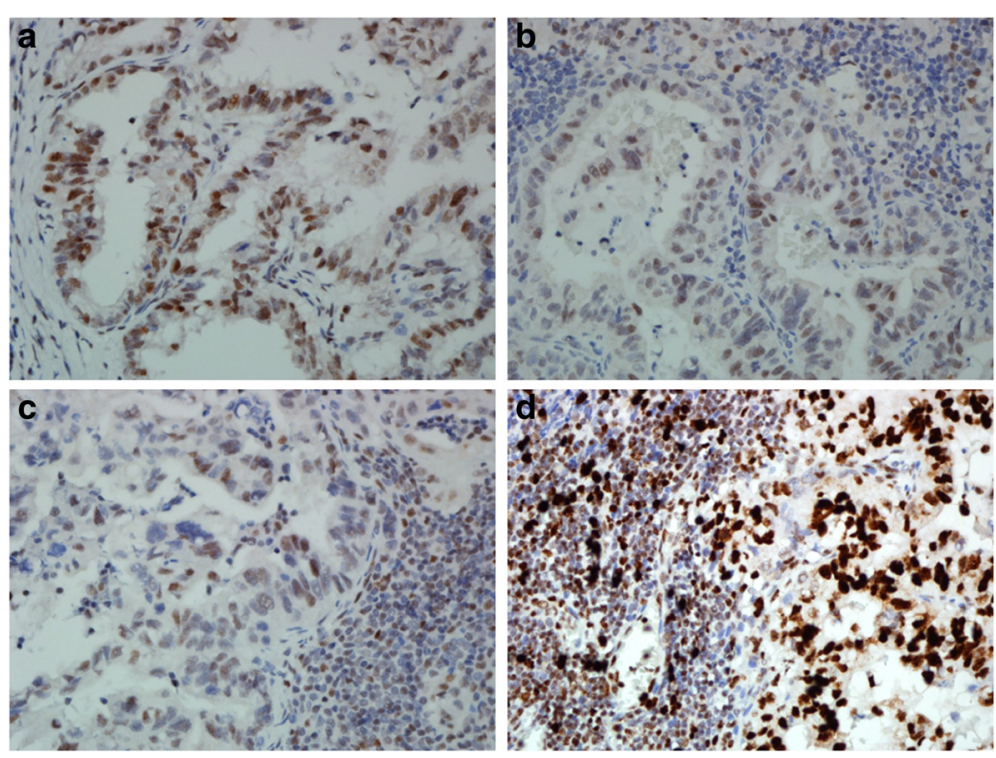

Fig. 3 Immunohistochemistry of MMR protein. The tumor cells preserved expression of MLH1 (a), MSH2 (b), PMS2 (c), and MSH6 (d); original magnification $\times 400$ 

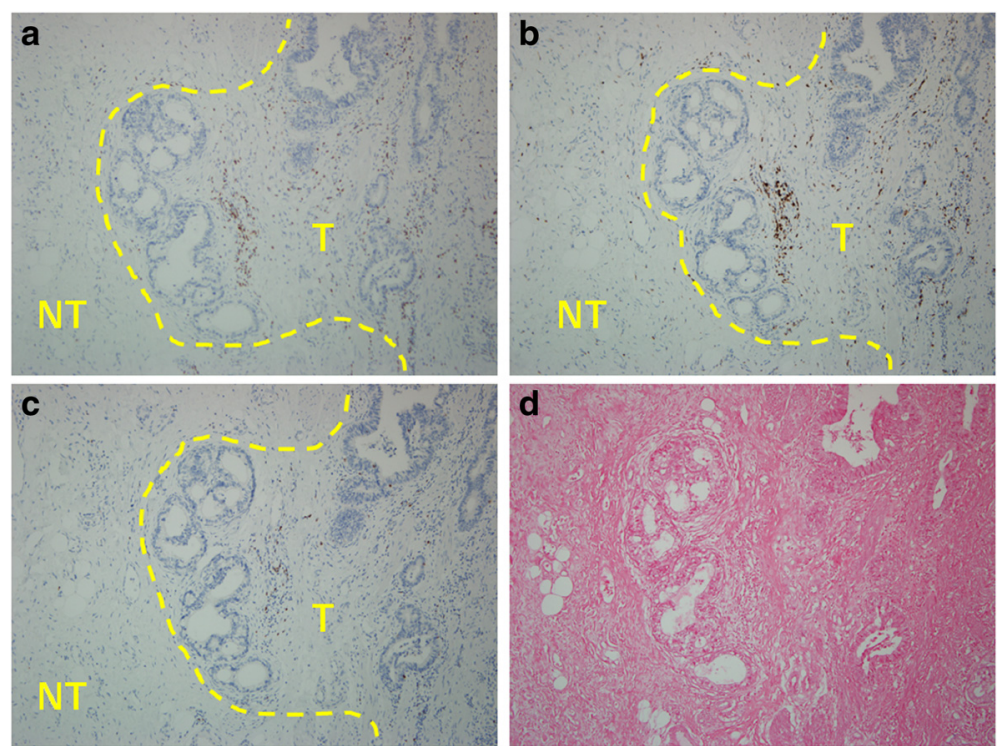

Fig. 4 Tumor-infiltrating lymphocytes and EBV status. The invasive front is highlighted by a yellow dashed line, which separates the tumor part ( $T$ ) from the nontumor part (NT). Few CD3(+) tumor-infiltrating lymphocytes (brown spot) (a). The infiltrating CD3(+) cells were composed mainly of CD4(+) cells (brown spot) (b) and a few CD8(+) cells (brown spot) (c). The invasive front had only a few lymphocytes. Most of the lymphocytes were scattered between tumor nests rather than within tumor nests. EBER in situ hybridization revealed no evidence of EBV infection in the tumor cells (positive is denoted by a dark blue spot in nuclei) $(\mathbf{d})$; original magnification: $\times 100$

PD-L1 has been reported to be overexpressed in EBV-associated malignancies, such as EBV-associated lymphoproliferative diseases, nasopharyngeal carcinoma, and HHV8-associated primary effusion lymphoma $[24,25]$. The mechanisms underlying increased PD-L1 expression in Hodgkin lymphoma include genetic amplification of CD274 (encoding PD-L1) and constitutive AP1 signaling. The TCGA study also revealed that the amplification of CD274 and PDCD1LG2 (also encoding PD-L1 and PD-L2) was enhanced in the EBV-positive gastric cancer subgroup [15]. Thus, these cancers are

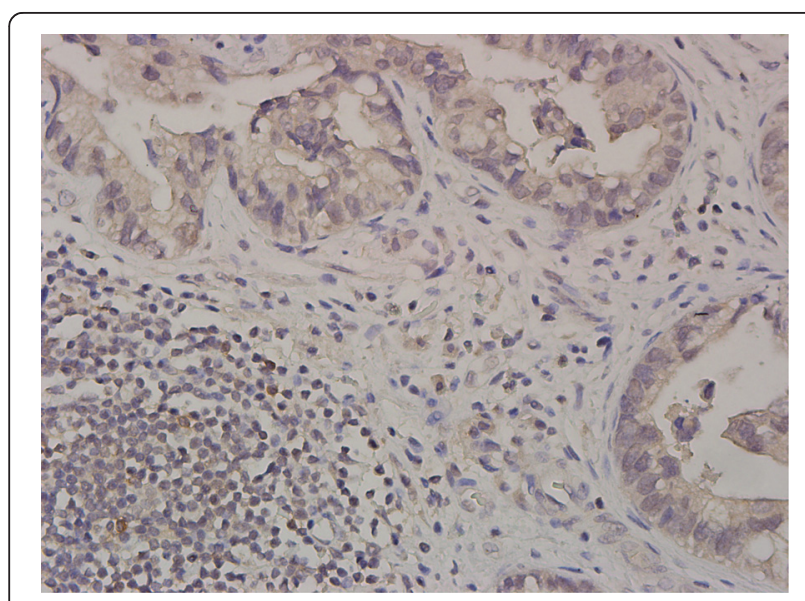

Fig. 5 Immunohistochemistry of PD-L1 protein. The tumor cells were negative for PD-L1 (B7-H1); original magnification $\times 400$ attractive targets for immune checkpoint therapy. In our patient, EBER in situ hybridization revealed absence of EBV in the tumor cells, and it is unlikely that the efficacy of anti-PD-1 therapy is affected by EBV-related CD274 and PDCD1LG2 amplification.

\section{Conclusions}

In conclusion, we report the case of a patient with pMMR and MSS gastric cancer who exhibited a confirmed objective response to PD-1 blockade, pembrolizumab monotherapy. Our case report indicates that mismatch repair proficiency and microsatellite stability may not be predictive to resistance of anti-PD-1 therapy, and factors other than $\mathrm{dMMR}$ and EBV infection may contribute to the response to anti-PD-1 therapy.

\section{Consent for publication}

Written informed consent was obtained from the patient for publication of this case report and any accompanying images. A copy of the written consent is available for review by the Editor-in-Chief of this journal. The institutional review board of National Taiwan University Hospital approved the study.

\section{Abbreviations}

CRC: colorectal cancer; CT: computed tomography; dMMR: deficient mismatch repair; EBV: Epstein-Barr virus; EBER: Epstein-Barr virus-encoded small RNA; EGJ: esophagogastric junction; IHC: immunohistochemistry; PD-1: programmed death-1; PD-L1: programmed death ligand-1; PMMR: mismatch repair-proficient; MSI: microsatellite instability; MSS: microsatellite stable; POLE: polymerase epsilon; TCGA: the Cancer Genome Atlas; TLL: tumor-infiltrating lymphocytes. 


\section{Competing interests}

The authors declare that they have no competing interests.

\section{Authors' contributions}

Dr. Yeh had full access to all of the data in the study and takes responsibility for the integrity of the data and the accuracy of the data analysis. KH Yeh and $\mathrm{KH}$ Chen did the study concept, design, and drafting of the manuscript. KH Yeh, KH Chen, CT Shun, and CT Yuan did the acquisition, analysis, and interpretation of data. LH Tseng did the genetic testing of microsatellite instability and POLE mutations. All authors read and approved the final manuscript.

\section{Funding}

This study was supported by a grant from Center of Excellence for Cancer Research (2014 to 2017), National Taiwan University Hospital (MOHW105-TDU-B-211-134004).

\section{Author details}

'Department of Oncology, National Taiwan University Hospital, 7, Chun-Shan S Rd, Taipei 10002, Taiwan. 'Department of Pathology, National Taiwan University Hospital, Taipei, Taiwan. ${ }^{3}$ Department of Medical Genetics, National Taiwan University Hospital, Taipei, Taiwan. ${ }^{4}$ National Taiwan University Cancer Center, Taipei, Taiwan. ${ }^{5}$ Department of Forensic Medicine, National Taiwan University, Taipei, Taiwan. ${ }^{6}$ Graduate Institute of Oncology, National Taiwan University, Taipei, Taiwan. ${ }^{7}$ Forensic Medicine, College of Medicine, National Taiwan University, Taipei, Taiwan.

Received: 18 February 2016 Accepted: 15 March 2016 Published online: 24 March 2016

\section{References}

1. Hodi FS, O'Day SJ, McDermott DF, Weber RW, Sosman JA, Haanen JB, Gonzalez R, Robert C, Schadendorf D, Hassel JC. Improved survival with ipilimumab in patients with metastatic melanoma. N Engl J Med. 2010; 363(8):711-23.

2. Topalian SL, Hodi FS, Brahmer JR, Gettinger SN, Smith DC, McDermott DF, Powderly JD, Carvajal RD, Sosman JA, Atkins MB. Safety, activity, and immune correlates of anti-PD-1 antibody in cancer. N Engl J Med. 2012; 366(26):2443-54

3. Le DT, Uram JN, Wang $H$, Bartlett BR, Kemberling $H$, Eyring AD, Skora AD, Luber BS, Azad NS, Laheru D. PD-1 blockade in tumors with mismatchrepair deficiency. N Engl J Med. 2015;372(26):2509-20.

4. Ansell SM, Lesokhin AM, Borrello I, Halwani A, Scott EC, Gutierrez M, Schuster SJ, Millenson MM, Cattry D, Freeman GJ. PD-1 blockade with nivolumab in relapsed or refractory Hodgkin's lymphoma. N Engl J Med. 2015:372(4):311-9.

5. Brahmer J, Reckamp KL, Baas P, Crino L, Eberhardt WE, Poddubskaya E, Antonia S, Pluzanski A, Vokes EE, Holgado E. Nivolumab versus docetaxel in advanced squamous-cell non-small-cell lung cancer. N Engl J Med. 2015; 373(2):123-35.

6. Larkin J, Chiarion-Sileni V, Gonzalez R, Grob JJ, Cowey CL, Lao CD, Schadendorf D, Dummer R, Smylie M, Rutkowski P. Combined nivolumab and ipilimumab or monotherapy in untreated melanoma. N Engl J Med. 2015;373(1):23-34

7. Brahmer JR, Tykodi SS, Chow LQ, Hwu WJ, Topalian SL, Hwu P, Drake CG, Camacho LH, Kauh J, Odunsi K. Safety and activity of anti-PD-L1 antibody in patients with advanced cancer. N Engl J Med. 2012;366(26):2455-65.

8. Lynch HT, de la Chapelle A. Hereditary colorectal cancer. N Engl J Med. 2003:348(10):919-32

9. Llosa NJ, Cruise M, Tam A, Wicks EC, Hechenbleikner EM, Taube JM, Blosser $\mathrm{RL}$, Fan $\mathrm{H}$, Wang $\mathrm{H}$, Luber BS. The vigorous immune microenvironment of microsatellite instable colon cancer is balanced by multiple counterinhibitory checkpoints. Cancer discovery. 2015;5(1):43-51.

10. Kim H, Jen J, Vogelstein B, Hamilton SR. Clinical and pathological characteristics of sporadic colorectal carcinomas with DNA replication errors in microsatellite sequences. Am J Pathol. 1994;145(1):148-56.

11. Hofmann M, Stoss $O$, Gaiser T, Kneitz H, Heinmoller P, Gutjahr T, Kaufmann $\mathrm{M}$, Henkel T, Ruschoff J. Central HER2 IHC and FISH analysis in a trastuzumab (Herceptin) phase II monotherapy study: assessment of test sensitivity and impact of chromosome 17 polysomy. Journal of clinical pathology. 2008;61(1):89-94.
12. Tsai JH, Lin YL, Cheng YC, Chen CC, Lin LI, Tseng LH, Cheng ML, Liau JY, Jeng YM. Aberrant expression of annexin A10 is closely related to gastric phenotype in serrated pathway to colorectal carcinoma. Modern pathology. 2015;28(2): 268-78.

13. Shi SJ, Wang LJ, Wang GD, Guo ZY, Wei M, Meng YL, Yang AG, Wen WH. $\mathrm{B} 7-\mathrm{H} 1$ expression is associated with poor prognosis in colorectal carcinoma and regulates the proliferation and invasion of HCT116 colorectal cancer cells. PLoS One. 2013;8(10):e76012.

14. Bang YJ, Shankaran V, Geva R, Yang AG, Wen WH. Relationship between PD-L1 expression and clinical outcomes in patients with advanced gastric cancer treated with the anti-PD-1 monoclonal antibody pembrolizumab (MK-3475) in KEYNOTE-012. J Clin Oncol. 2015;33(suppl; abstr 4001).

15. Cancer Genome Atlas Research N. Comprehensive molecular characterization of gastric adenocarcinoma. Nature. 2014;513(7517):202-9.

16. Kim KJ, Jung HY, Oh MH, Cho H, Lee JH, Lee HJ, Jang SH, Lee MS. Loss of ARID1A expression in gastric cancer: correlation with mismatch repair deficiency and clinicopathologic features. Journal of gastric cancer. 2015; 15(3):201-8

17. van Grieken NC, Aoyama T, Chambers PA, Bottomley D, Ward LC, Inam I, Buffart TE, Das K, Lim T, Pang B. KRAS and BRAF mutations are rare and related to DNA mismatch repair deficiency in gastric cancer from the East and the West: results from a large international multicentre study. $\mathrm{Br} J$ Cancer. 2013;108(7):1495-501.

18. Wu MS, Lee CW, Shun CT, Wang HP, Lee WJ, Chang MC, Sheu JC, Lin JT. Distinct clinicopathologic and genetic profiles in sporadic gastric cancer with different mutator phenotypes. Genes Chromosomes Cancer. 2000:27(4):403-11.

19. Simpson AJ, Caballero OL, Pena SD. Microsatellite instability as a tool for the classification of gastric cancer. Trends Mol Med. 2001;7(2):76-80.

20. Snyder A, Makarov V, Merghoub T, Yuan J, Zaretsky JM, Desrichard A, Walsh LA, Postow MA, Wong P, Ho TS. Genetic basis for clinical response to CTLA4 blockade in melanoma. N Engl J Med. 2014;371(23):2189-99.

21. Rizvi NA, Hellmann MD, Snyder A, Kvistborg P, Makarov V, Havel J, Lee W, Yuan J, Wong P, Ho TS. Cancer immunology. Mutational landscape determines sensitivity to PD-1 blockade in non-small cell lung cancer. Science (New York, NY). 2015;348(6230):124-8.

22. Palles C, Cazier JB, Howarth KM, Domingo E, Jones AM, Broderick P, Kemp Z, Spain SL, Guarino E, Salguero I. Germline mutations affecting the proofreading domains of POLE and POLD1 predispose to colorectal adenomas and carcinomas. Nat Genet. 2013;45(2):136-44.

23. Howitt BE, Shukla SA, Sholl LM, Ritterhouse LL, Watkins JC, Rodig S, Stover E, Strickland KC, D'Andrea AD, Wu CJ. Association of polymerase e-mutated and microsatellite-instable endometrial cancers with neoantigen load, number of tumor-infiltrating lymphocytes, and expression of PD-1 and PD-L1. JAMA oncology. 2015;1(9):1319-23.

24. Chen BJ, Chapuy B, Ouyang J, Sun HH, Roemer MG, Xu ML, Yu H, Fletcher CD, Freeman GJ, Shipp MA. PD-L1 expression is characteristic of a subset of aggressive B-cell lymphomas and virus-associated malignancies. Clinical cancer research. 2013:19(13):3462-73.

25. Green MR, Rodig S, Juszczynski P, Ouyang J, Sinha P, O'Donnell E, Neuberg D, Shipp MA. Constitutive AP-1 activity and EBV infection induce PD-L1 in Hodgkin lymphomas and posttransplant lymphoproliferative disorders: implications for targeted therapy. Clinical cancer research. 2012;18(6):1611-8.

\section{Submit your next manuscript to BioMed Central and we will help you at every step:}

- We accept pre-submission inquiries

- Our selector tool helps you to find the most relevant journal

- We provide round the clock customer support

- Convenient online submission

- Thorough peer review

- Inclusion in PubMed and all major indexing services

- Maximum visibility for your research

Submit your manuscript at www.biomedcentral.com/submit 